React. Kinet. Catal. Lett., Vol. 20, Nos. 3 -4 (1982)

\title{
DESCRIPTION OF NONISOTHERMAL REACTIONS IN TERMS OF MARCELIN-DE-DONDER KINETICS AND ITS GENERALIZATIONS
}

\author{
V.I. Bykov, A. N. Gorban and G.S. Yablonskii* \\ Computing Center, Krasnoyarsk, *Institute of Catalysis, Novosibirsk, USSR \\ Received January 4, 1982 \\ Accepted March 19, 1982
}

\begin{abstract}
A general form for the description of nonisothermal reactions in closed chemical systems in terms of the Marcelin-de-Donder kinetics and explicit forms of the Lyapunov functions for the systems treated under various conditions are suggested.
\end{abstract}

Дана общая форма описания неизотермических реакций в закрытой химической системе в рамках кинетики типа Марселена-де-Донде: В явном виде выписањы для различных условий функции Ляпунова рассмотренных систем.

It is likely that the most general (and reasonable) type of chemical kinetic equations was given in Ref. $/ 1 /$. It is a kinetics which is positive with respect to chemical potentials. In terms of this kinetics, the rate $\mathrm{W}(\mathrm{C}, \mathrm{T})$ of the reaction

$$
\alpha_{1} A_{1}+\ldots+\alpha_{n} A_{n} \rightleftharpoons \beta_{1} A_{1}+\ldots+\beta_{n} A_{n}
$$

should meet the condition

$$
\mathrm{W}(\mathrm{c}, \mathrm{T}) \sum_{\mathrm{i}=1}^{\mathrm{n}} \gamma_{\mathrm{i}} \mu_{\mathrm{i}}(\mathrm{c}, \mathrm{T}) \leqslant 0, \quad \gamma_{\mathrm{i}}=\beta_{\mathrm{i}}-\alpha_{\mathrm{i}}
$$

In this case equality (1) is attained only at $\Sigma \gamma_{i} \mu_{i}=0$ (c is the vector of concentrations, $\mathrm{T}$ is the temperature and $\mu_{\mathrm{i}}(\mathrm{c}, \mathrm{T})$ is the potential of the $\mathrm{i}$-th substance). For our purposes it is more convenient to consider-a potential differing from chemical ones by the RT factor rather than chemical potentials themselves. The former were designated $/ 1 /$ as pseudochemical potentials. 
Condition (1) is satisfied, e.g., by:

$$
\mathrm{W}(\mathrm{c} T)=\mathrm{W}^{\circ}(\mathrm{c}, \mathrm{T})\left(\exp \Sigma \alpha_{\mathrm{i}} \mu_{\mathrm{i}}-\exp \Sigma \beta_{\mathrm{i}} \mu_{\mathrm{i}}\right)
$$

where $W^{\circ}$ is an arbitrary nonnegative function, in this case $W^{\circ}(c, T)>0$ at the points where $\Sigma \gamma_{\mathrm{i}} \mu_{\mathrm{i}}(\mathrm{c}, \mathrm{T}) \neq 0$. Moreover, any sufficiently smooth function $W(\mathrm{c}, T)$ satisfying eq. (1), can be represented as eq. (2) if the function $\Sigma \gamma_{i} \mu_{i}$ has no positive critical points. Kinetic laws of type (2) are the natural generalizations of the Marcelin-de-Donder kinetics $/ 1-3 /$ used in Refs. $/ 4-5 /$ for nonideal heterogeneous catalytic reactions.

The dynamics of closed systems with kinetic laws of type (2) is similar to the behavior of the Marcelin-de-Donder kinetic systems. In particular, all results of Refs. /2, 3/ are transferred to the case under consideration (assuming that $\left.W^{\circ}(c, T)>0\right)$. Partially this transfer was made in Ref. $/ 5 /$.

The purpose of the present communication was to illustrate the way to describe nonisothermal kinetics in terms of eq. (2) and to present explicit expressions for functions similar to that of free energy under various conditions. Note that some attempts to describe the nonisothermal kinetic processes in terms of nonideal kinetic laws are known from the literature (e.g. Ref. /6/). However, we believe them to be unsatisfactory due to several reasons. For example, they have not taken into consideration the dependence of the thermal capacity of the mixture on its composition and the entropy (exponential) factor in the temperature dependence of the equilibrium constant $/ 7 /$ :

$$
\mathrm{K}_{\mathrm{eq} 1}=A T^{\Delta \mathrm{CV} / \mathrm{R}} \exp (-\mathrm{E} / \mathrm{RT})
$$

The simplest form have kinetic equations in terms of the amounts of substances $\mathrm{N}_{\mathrm{i}}$ :

$$
\dot{N}=V \Sigma W_{s} \gamma_{s}
$$

where $\mathrm{V}$ is the mixture volume, $\mathrm{W}_{\mathrm{s}}$ is the rate of the s-th reaction, $\gamma_{\mathrm{s}}$ is the stoichiometric vector of the $s$-th reaction $\left(\left(\gamma_{s}\right)_{i}=\beta_{s i}-a_{s i}\right), N$ is the vector of amounts of substances $\mathrm{N}_{\mathrm{j}}$. Under constant conditions (constant volume or pressure, isothermal or adiabatic conditions) all variables and functions $c, T, V, S$ and $W$ can be expressed through the vector of the composition $\mathrm{N}$ and the values which remain unchanged during the process. In what follows, we assumed this to have been done. 
One should meet the symmetry condition:

$$
\frac{\partial \mu_{i}}{\partial N_{j}}=\frac{\partial \mu_{j}}{\partial N_{i}}
$$

From eq. (5) under various conditions, limitations for the type of the function $\mu_{i}$ follow. Let us examine them for the case of ideal gases.

$$
\text { 1. } \mathrm{V}, \mathrm{T}=\text { const. } \quad \frac{\partial \mu_{\mathrm{i}}}{\partial \mathrm{C}_{\mathrm{j}}}=\frac{\partial \mu_{\mathrm{j}}}{\partial \mathrm{C}_{\mathrm{i}}}
$$

2. $P, T=$ const. $P$ is the pressure . Taking into account eq. (6), we obtain that $\Sigma C_{k} \frac{\partial \mu_{i}}{\partial C_{k}}$ is independent of i, i.e. $\Sigma C_{k} \frac{\partial}{\partial C_{k}}\left(\mu_{i}-\mu_{j}\right)=0$.

3. $\mathrm{V}, \mathrm{U}=$ const. (The system is thermoisolated). $U$ is the internal energy of the system (also including chemical energy).

$$
\left(u_{i} / T+C_{V i}\right)^{-1} \frac{\partial \mu_{i}}{\partial T}=\left(u_{j} / T+C_{V j}\right)^{-1} \frac{\partial \mu_{j}}{\partial T}
$$

where $C_{V i}$ is the specific thermal capacity of the substance $A_{i}, u_{i}(J / m o l)$ is the "chemical energy" of $A_{i}$ (energy of the ground state).

4. $\mathrm{P}, \mathrm{H}=$ const. (The system is thermoisolated). $\mathrm{H}=\mathrm{U}+\mathrm{PV}$ is the enthalpy.

$$
\left(\mathrm{u}_{\mathrm{i}} / \mathrm{T}+\mathrm{C}_{\mathrm{Vi}}+\mathrm{R}\right)^{-1}\left(\frac{\partial \mu_{\mathrm{i}}}{\partial \mathrm{T}}-\frac{1}{\mathrm{~T}} \Sigma \mathrm{c}_{\mathrm{k}} \frac{\partial \mu_{\mathrm{i}}}{\partial \mathrm{C}_{\mathrm{k}}}\right)=\text { const. }
$$

(is independent of i)

If the kinetics is ideal (the mass action law is valid), then:

$$
\mu_{i}=\ln c_{i}+\varphi_{i}(T)
$$

Then from eqs. (5-8) for the constants $\mathrm{C}_{\mathrm{Vi}}$ we have

$$
\mu_{i}=\ln c_{i}+\frac{u_{i}}{R T}+\frac{C_{V i}}{R} \ln T+\delta_{i}
$$


where $\delta_{i}$ is independent of $c$, T. If the specific thermal capacities $\mathrm{C}_{\mathrm{Vi}}$ depend on $\mathrm{T}$, then after similar calculations we obtain

$$
\mu_{\mathrm{i}}=\ln \mathrm{c}_{\mathrm{i}}+\frac{\mathrm{u}_{\mathrm{i}}}{\mathrm{RT}}-\frac{1}{\mathrm{R}} \int_{\mathrm{To}}^{\mathrm{T}} \frac{\mathrm{C}_{\mathrm{Vi}}(\tau)}{\tau} \mathrm{d} \tau+\delta_{\mathrm{i}}
$$

where $T_{0}$ is some initial temperature. Let us designate the integral in eq. (11) by $S_{i}$. Finally:

$$
\mu_{i}=\ln v_{i}+u_{i} / R T-S_{i} / R+\delta_{i}
$$

According to eqs. $(2,12)$, we have

$$
\begin{aligned}
W(c, T)= & W^{\circ}(c, T)\left(k^{+} \exp \left(-\frac{1}{R} \Sigma \alpha_{i}\left(S_{i}-u_{i} / T\right)\right) \Pi_{c_{i}}^{\alpha_{i}}-\right. \\
& \left.k^{-} \exp \left(-\frac{1}{R} \Sigma \beta_{i}\left(S_{i}-u_{i} / T\right)\right) \Pi c_{i}^{\beta_{i}}\right),
\end{aligned}
$$

where $\mathrm{k}^{+}=\exp \Sigma \alpha_{\mathrm{i}} \delta_{\mathrm{i}}, \mathrm{k}^{-}=\Sigma \beta_{\mathrm{i}} \delta_{\mathrm{i}}$. The equilibrium constant, as is generally the case, is of the form (Ref. /3/):

$$
K_{\text {eql }}=A \exp (\Delta S-\Delta E / T) / R
$$

where $\Delta S=\Sigma \gamma_{\dot{i}} S_{i}, \Delta E=\Sigma \gamma_{i} u_{i}$.

From symmetry conditions (5), there follows the existence of such function $G(N)$ that $\mu_{i}=\frac{\partial G}{\partial N_{i}}$. It appears that $G$ is the Lyapunov function for eq. (3) and its time derivative due to system (4) is $\dot{G}=\Sigma W_{s}\left(\ln W_{s}^{+}-\ln W_{s}\right) \leqslant 0$. Let us write down the functions $G$ for all conditions examined:

1. $\mathrm{V}, \mathrm{T}=$ const. $\quad \mathrm{G}=\Sigma \mathrm{N}_{\mathrm{i}}\left(\mu_{\mathrm{i}}-1\right)$

2. $\mathrm{P}, \mathrm{T}=$ const. $\quad \mathrm{G}=\Sigma \mathrm{N}_{\mathrm{i}} \mu_{\mathrm{i}}$

Functions $(15,16)$ have been traditionally applied for studies concerning the dynamics of closed systems beginning with Ref. /8/ (Refer also to /9, 10/). 
3. $\mathrm{V}, \mathrm{U}=$ const. $\quad \mathrm{G}=\Sigma \mathrm{N}_{\mathrm{i}}\left(\ln \left(\mathrm{N}_{\mathrm{i}} / \mathrm{V}\right)+\delta_{\mathrm{i}}-1\right)-\mathrm{C}_{\mathrm{V}}(\ln \mathrm{T}+1) / \mathrm{R}$,

where

$$
\mathrm{C}_{\mathrm{V}}=\Sigma \mathrm{C}_{\mathrm{Vi}} \mathrm{N}_{\mathrm{i}}, \mathrm{T}=\left(\mathrm{U}-\Sigma \mathrm{u}_{\mathrm{i}} \mathrm{N}_{\mathrm{i}}\right) / \mathrm{C}_{\mathrm{V}}
$$

4. $\mathrm{P}, \mathrm{H}=$ const. $\quad \mathrm{G}=\Sigma \mathrm{N}_{\mathrm{i}}\left(\ln \mathrm{N}_{\mathrm{i}}-\ln \left(\Sigma \mathrm{N}_{\mathrm{i}}+\delta_{\mathrm{i}}-\ln (\mathrm{R} / \mathrm{P})\right)-\mathrm{C}_{\mathrm{P}}(\ln \mathrm{T}+1) / \mathrm{R}\right.$

where

$$
C_{P}=\Sigma\left(C_{V i}+R\right) N_{i}, \quad T=\left(H-\Sigma u_{i} N_{i}\right) / C_{P} .
$$

It is not difficult to generalize eqs. $(15-18)$ for the case of variable specific thermal capacities $C_{V i}(T)$ or nonideal kinetics at $V, T=$ const. Note also that $\tilde{u}_{i}$ which is the energy (enthalpy) of one mole at some temperature $T_{0}$ is often used rather than $u_{\mathrm{i}}$. For simplicity's sake, the respective transformations are omitted.

Consequently, eq. (13) permits to write down the nonisothermal kinetic equation as eq. (4). In this case the reaction rates are determined by a nonideal kinetic law, which is the generalization of the Marcelin-de-Donder kinetics.

The authors are thankful to S. E. Gilev for useful discussions.

\section{REFERENCES}

1. M. Feinberg: Arch. Ration. Mech. Anal., 46, 1 (1972).

2. T. A. Akramov, V. I. Bykov, G. S. Yablonskii: in Mathematical Problems of Chemistry, Part I, p. 206, Novosibirsk 1975.

3. V. I. Bykov, A. N. Gorban, V. I. Dimitrov: React. Kinet. Catal. Lett., 12, 19 (1979).

4. Yu. S. Snagovskii: Kinet. Katal., 21, 189 (1980).

5. A. G. Zyskin, Yu. S. Snagovskii, M. G. Slinko: Kinet. Katal., 22, 1031 (1981); React. Kinet. Catal. Lett., 17, 263 (1981).

6. T. A. Akramov: Dokl. Akad. Nauk SSSR, 244, 554 (1979).

7. L. D. Landau, E. M. Lifshits: Statistical Physics, p. 377. Nauka, Moskva 1964.

8. Ya. B. Zeldovich: Zh. Fiz. Khim., 11, 685 (1938).

9. A. I. Volpert: Qualitative Methods of the Treatment of Chemical Kinetic Equations. Preprint, Joint Institute of Chemical Physics, Chernogolovka 1976.

10. A. N. Gorban, G. S. Yablonskii, V. I. Bykov: in Mathematical Problens of Chemical Thermodynamics, p. 37, Nauka, Novosibirsk 1980. 